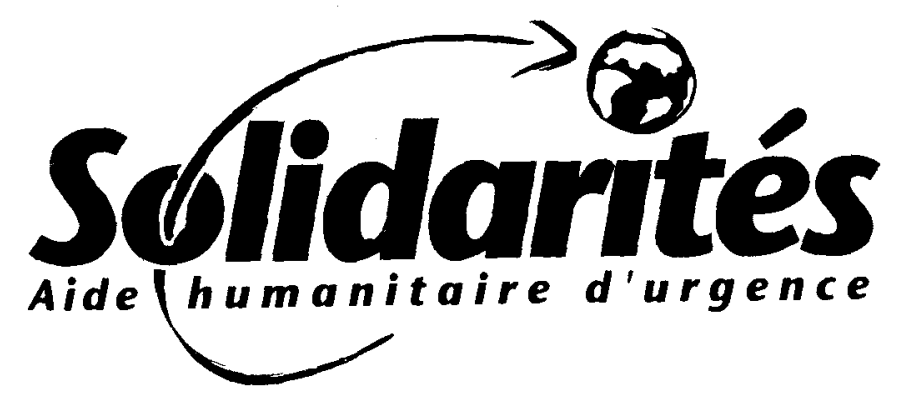

\title{
Hydrogeological problems in Kabul city
}

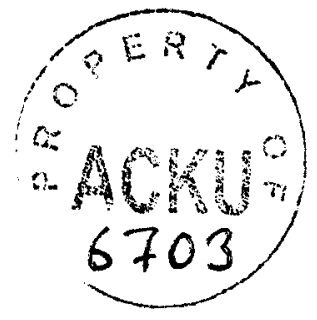

Engineer Ehsanulläh,

Date: 09-06-1996

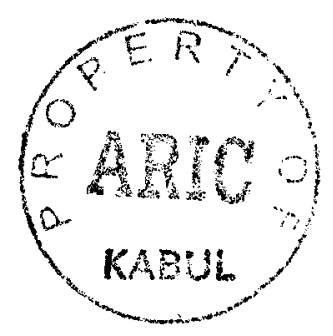


Water is a vital material which is playing an important role in human civilization. In view of this fact United Nations has announced the current decade as an International Decade of water, among all activities regarding water supply drinking water is the basic job to be done. The best resource of drinking water is, under ground water. Because the resources of ground water is persistent throughout of all seasons and is not in direct touch with atmosphere, so it has not been polluted.

Nowadays in some European countries like Austria $98 \%$ of drinking water comes from ground water. In Asian counties such as Iran, Afghanistan and India according to static, they use $56 \mathrm{~km}$ underground water for irrigation and domestic conventions.

As the hydrogeological construction of our country shows, that we can separate it in three ground water zones.

I- The central mountainous zone which is the main source of water flows off the country.

II- Artizean zone in the north of country.

III- Artizean zone in the south of country.

Kabul city belongs to the first mentioned zone. There are a lot of problems in Kabul city, regarding the regulation of Kabul Municipality $6.2 \mathrm{~m} / \mathrm{sec}$ of water is necessary for Kabul inhabitants.

In Kabul city there is aluvial deposits of quarternary as well as the Neogen or the most water bearing horizons. As I have explained the city with its present population need $6.2 \mathrm{~m} / \mathrm{sec}$ ground water. However out of this $14 \%$ was provided at the previous time and at the time being may be just $5-7 \%$. This quantity of water was exploted by Alaudin, Afshar and Bagrami water stations.

The rest poor people are using the surface water(top aquifer) this water is not so safe.

The water resources in the Neogen deposits due to their protection from being polluted is better to be utilized than that of the aluvial deposits of the quarternary age.

The nonexistence of a regular sewage in the city and due to dumping waste material in the ground by the local people, as well due to the use of chemical fertilization, the ground water in Kabul city is (used to be ) polluted. The other way of wasting ground water is abnormal using water bearing horizonts, in this type of using ground water the cone of depression is very rapidly developed and water level is coming down. 
In conclude it is going to be dwindled and drilled holes cue to be dehydrated.

Bactorialogical pollution is increasing from the periphearen of the valley to wards center as well as eastern direction to wards western to be sure about this fact we have researched increasing quantity of $\mathrm{NH} 4, \mathrm{No} 2, \mathrm{No} 3$ in ground water in the neogen deposit is naturally protected from being polluted.

Our investigation in this field will be continuing in the future.

At the end I want your attention to the way of solving above problems.

1 - to manage and rehabilitate previous water station, and built new ones which are shown in Hydrogeological maps.

2- To take care about sewage system of Kabul city, without this system we will lose all ground water, increasing the number of houses on the water bearing horizont shows we will pollute all aluvial horizonts.

3- To take care in distribution of water, not to drain all the water of a well ( thickness of water bearing horizont). 


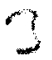 \\ Minute of the Conference dated 09-06-1996}

\section{1- Eng. Amin:}

Question-1:- What is the negative effects of digging wells on dynamic and static resource of water?

Answer: The fluctuation of water during the year is around on meter, the quantity of raining ( dynamic resource) during one year can compensate around 5 years static resource of water.

Question-2:- How is the movement of ground water during the year? Answer: Ground water has different kinds of movement during the year:

- When the surface of water in Kabul river com up, the water will move from the river to the ground where there are resources of the fresh water.

-When the surface of water during the year come down the water from the resource in ground will move to the river again.

2- Eng. Sakhi: Does the movement of ground water from west to east has any effect on fresh water?

Answer: If the fresh water is used in a large amount, it will give a negative effect on fresh water, it means that we have removed the barrier between fresh water and salty water and salty water move towad fresh water.

3-Eng. Sami: Can we block the border between fresh and saity water?

Anower: No, there are different reasons that we can't block the border between fresh and salty water;

- the breakage of the horizont in ground,

- the position of fresh water lenses in salty water,

- to keep balance between fresh und salty water,

When we use a large amount of fresh water, so the balance between fresh and salty water will change and the fresh water wil move toward salty water. Some times the fresh and salty water are available on eachother.

4- Eng. Sakhi: What are the properties of fresh and salty water?

Answer: Fresh water, salt and water ratio lg/iter.

Salty water, salt and water ratio $3 g$ liter.

5-Dr. Jean: How is the quality and pollution of water during 10-12 years?

Answer: The quality of water and the cause of poliution are different from one place to another, however the compound of $\mathrm{No} 2$ has a main effect on the pollution of water almost everywhere. 
6-Eng. Zabi: Can the septic tank cause the pollution of underground water?

Answer: It requires a very hard analysis to find out how can septic tank cause the poliution of underground water, but anyway the septic tank must be isolated in order to prevent the germ from coming down to horizont of the fresh water.

The water from septic tank ( 1nisolated) or from the surface of the ground can reach to underground water very soon in contrast, it takes long time to reach a germ to underground water.

7- Eng. Najibullah: How can we classify the surface and underground water?

Answer: The water exposed to atmosphere is classified under the title of surface water. The water unexposed to atmosphere is classified under the title of underground water.

8- Eng.Amin: What kind of movement does underground water have?

Answer: Underground water has two kinds of movement, Horizontal and Vertical movement.

9- Eng. Zabi: Why don't salty and fresh water mix with each other?

Answer: Viscosity, movement and the balance of the forces being formed during the movement cause the fresh and salty water not to mix with each other.

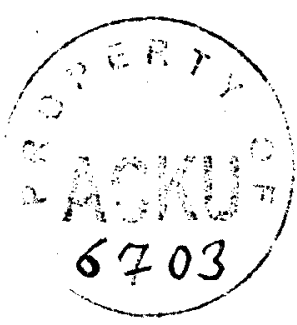

